\title{
Processing and storage of blood components: strategies to improve patient safety
}

\author{
This article was published in the following Dove Press journal: \\ International Journal of Clinical Transfusion Medicine \\ II August 2015 \\ Number of times this article has been viewed
}

\section{Ruby NI Pietersz \\ Pieter $F$ van der Meer \\ Department of Product and Process Development, Sanquin Blood Bank, Amsterdam, the Netherlands}

\begin{abstract}
This review focuses on safety improvements of blood processing of various blood components and their respective storage. A solid quality system to ensure safe and effective blood components that are traceable from a donor to the patient is the foundation of a safe blood supply. To stimulate and guide this process, National Health Authorities should develop guidelines for blood transfusion, including establishment of a quality system. Blood component therapy enabled treatment of patients with blood constituents that were missing, only thus preventing reactions to unnecessarily transfused elements. Leukoreduction prevents many adverse reactions and also improves the quality of the blood components during storage. The safety of red cells and platelets is improved by replacement of plasma with preservative solutions, which results in the reduction of isoantibodies and plasma proteins. Automation of blood collection, separation of whole blood into components, and consecutive processing steps, such as preparation of platelet concentrate from multiple donations, improves the consistent composition of blood components. Physicians can better prescribe the number of transfusions and therewith reduce donor exposure and/or the risk of pathogen transmission. Pathogen reduction in cellular blood components is the latest development in improving the safety of blood transfusions for patients.
\end{abstract}

Keywords: blood components, red cell concentrates, platelet concentrates, plasma, transfusion, safety

\section{National guidelines and quality system}

General circumstances such as weather conditions, quality of roads, reliability of power and water supply, and ways of transportation differ between countries and greatly influence the access to medical care, including a safe and sufficient blood supply. In countries with high-level care and treatment, the blood supply should support advanced surgical and medical procedures with specific blood components, while with low-level care, whole blood is often used for the management of more basic transfusion needs such as severe anemia and acute bleeding.

Good Manufacturing Practices (GMPs) for the manufacturing of pharmaceutical drugs has been introduced in the 1960 s to ensure consistent and reproducible products with traceability from the source materials to the final destination of the drug. In the 1980s, blood components were considered medicinal products, and international guidelines for GMP for blood supply facilities were developed, and current updates have to be followed (current GMP [cGMP]). ${ }^{1,2}$

Even services that collect only a few units of blood should be aware of GMP, and as a start, they should at least have written standard procedures (reviewed and updated on a regular basis) and documentation for all steps of the transfusion chain.
Correspondence: Pieter F van der Mee Department of Product and Process Development, Sanquin Blood Bank, Plesmanlaan I25, PO Box 9137, I006 AC Amsterdam, the Netherlands

$\mathrm{Tel}+3 \mid 205123818$

Fax +31 206178080

Email p.vandermeer@sanquin.nl 
In larger centers, multiple materials and methods are applied to collect blood from donors, to process and store the various blood components, and to test for the transfusion of transmissible diseases. With a very variable source material, that is, donors' whole blood, very strict specifications for the whole blood and each component are needed. ${ }^{3-5}$ Processes and procedures have to be defined, documented, and validated, ${ }^{1,6-9}$ and extensive training and certification of staff are necessary to ensure to obtain safe and consistent transfusion products that are backed by a full trail of documentation of the chain of events from donor to transfusion of the patient. ${ }^{10}$ Preferably, all documentation should be stored electronically in a validated blood bank information system. ${ }^{11,12}$

Health authorities should recognize the importance of blood transfusion and adapt the international guidelines mentioned earlier ${ }^{1-12}$ to national guidelines, and thereby offer resources to the level of care that is necessary for their country. Health inspectorates should verify the execution and implementation of these guidelines at certified blood transfusion institutions on a regular base.

In summary, quality systems including GMP, Good Laboratory Practice (GLP), Good Clinical Practice (GCP), Good Documentation Practice (GDocP), and Good Distribution Practice (GDP) are now cornerstones for safety of a state-of-the-art blood transfusion service that meet national requirements based on the international guidelines and recommendations.

\section{Donors}

For many years voluntary, non-remunerated donors have been considered to be the safest with regard to infectious diseases risks. Van der $\mathrm{Bij}$ et $\mathrm{al}^{13}$ compared voluntary and non-remunerated first-time donors with repeat donors who were found to be positive for transfusion-transmitted infections (TTIs) from 1995 to 2003 in the Netherlands. The percentage of candidate first-time donors with confirmed positive hepatitis B virus tests was much higher than in repeat donors, namely, $80 \%$ in first-time donors (222 first-time donors out of 279 cases in total), and the same was true for hepatitis $\mathrm{C}$ virus $(85 \%$; 105/123) and human T-lymphotropic virus $(67 \% ; 14 / 21)$, respectively. The percentage of repeat donors who tested positive for human immunodeficiency virus was higher $(79 \% ; 26$ repeat donors out of 33 cases in total), and for syphilis, it was equal at 50\% (62/122). Similar results were found for human immunodeficiency virus tested with nucleic acid testing worldwide. ${ }^{14,15}$ Thus, first-time donors, even voluntary and non-remunerated, have a higher risk than repeat donors for the majority of TTIs; this may be due to underreporting risk behavior. ${ }^{13}$ In some countries, first performing a medical checkup and complete testing of candidate donors before any blood is drawn is still under debate; the donor is only invited for blood collection if the initial test results are negative. ${ }^{13,16} \mathrm{~A}$ further advantage of only testing first-time donors and not collecting a bag of blood is cost saving of the blood bag and consecutive processing if a test turns up positive, but a disadvantage may be that donors do not show up for a second time. ${ }^{16}$ Allain ${ }^{17}$ showed that reliable repeat replacement donors (who only donate blood if family or friends needed or received a unit of blood) had as many positive test results as voluntary donors, as reported for the sub-Saharan countries. He also argued that only repeat donation improved blood viral safety. ${ }^{18}$ However, first-time donors are always needed, and extensive information about risk behavior, TTIs, and blood transfusion should timely be provided to candidate donors and discussed privately prior to donation.

Another safety aspect of repeat donors is the possibility to repeatedly test for $\mathrm{ABO}$ and other red cell antigens, and eventually human leukocyte antigens (HLAs) and human platelet antigens (HPAs) to build a (rare) donor database. Also, blood collections and inventories can be steered more precisely if the blood groups are known. ${ }^{19}$

Generally, these days, reliable repeat donors - either voluntary or replacement donors - with data recorded in (an electronic) database are the safest donors for the reasons illustrated earlier.

\section{Whole blood collection and component processing}

Approximately a century ago, it was recognized that blood transfusion was only possible if the donated blood was not clotted. Citrate mixtures were developed at first only to anticoagulate the blood, allowing storage for a few days. ${ }^{20}$ Later, "nutrients" such as dextrose for the red cells were added to the formula, extending the storage time of whole blood in acid citrate dextrose solution to 3 weeks. ${ }^{20}$ In the $1960 \mathrm{~s}$, phosphate and adenine were applied in citrate-phosphatedextrose-adenine- 1 because of which the storage time was extended to 4 weeks. ${ }^{21}$

During World War II, sterile glass bottles with a rubber stopper that was kept in place by a metal cap were used on a large scale to collect and store whole blood. ${ }^{20}$ To collect blood and later in the process to remove plasma or other components, an air vent and a long needle had to be inserted through this rubber stopper. Therefore, collection 
and processing took place in an open system, with a high chance of bacterial contamination that ranged between $2 \%$ and 5\%. ${ }^{22,23}$ Scarce case reports describe fatal events after transfusion of contaminated blood due to various omissions in the sterilization procedures, blood collection, or storage..$^{22-24}$ For safety reasons, the storage time was reduced to 24 hours after opening when the component was stored at $2{ }^{\circ} \mathrm{C}-6^{\circ} \mathrm{C}$ and to 6 hours when storage took place at ambient temperature. This measure is still in place if the closed system of a transfusion product is opened. Blood processing became possible in a closed system only when fully integrated steam sterilized systems, consisting of multiple plastic bags connected by tubing, came onto the market in the $1960 \mathrm{~s} .{ }^{25}$ At that time, this was a major step forward regarding patient safety.

Today, automated equipment for collecting whole blood in plastic bags, mixing, measuring the blood flow, weighing the blood components, calculating the collection time, and documenting all data has been developed and has contributed to the safety by collecting a standardized volume of blood.

\section{Rationale for blood components}

In high-care countries, the need for Factor VIII for patients with hemophilia, either as cryoprecipitate or as Factor VIII concentrate obtained by large-scale fractionation of plasma, has forced the general agreement that the efficient and economical use of blood implies that patients are transfused only with the specific blood component the patient requires, in general red cells, platelets, or plasma. Advantages of component therapy are as follows:

- The recipients can be treated with only those blood components that they are lacking, thereby reducing the occurrence of adverse transfusion reactions such as febrile reactions, hemolytic reactions, HLA alloimmunization, bacterial or viral transmission, transfusion-related acute lung injury (TRALI), and volume overload.

- More than one patient can be treated with components derived from one donation.

- Plasma that often is not immediately needed for transfusion can be used for manufacturing of clotting factor concentrates such as Factor VIII concentrate.

Another advantage of processing components is that storage-induced changes start within 24 hours in whole blood: platelets and clotting factors decrease quickly, neutrophils disintegrate, and microaggregates (consisting of platelets, leukocytes, fibrin, and captured red cells) will form. ${ }^{26}$ Quick cooling (with butane-1,4-diol plates) slows down this process. During longer storage, due to the metabolism of the cells, glucose is consumed and lactic acid is formed, which causes the $\mathrm{pH}$ to decrease. Potassium levels in plasma and free hemoglobin will increase, and (labile) clotting factors will decrease. ${ }^{20}$ The microaggregates in stored blood caused severe adult respiratory distress syndrome in recipients, and for that reason, in the 1970s, $40 \mu \mathrm{m}$ microaggregate filters in the administration set were applied to prevent these reactions. $^{22,26}$

To prevent the formation of microaggregate during storage and provided that plastic collection bag systems are available, whole blood should therefore be processed into components, during which process the majority of leukocytes and platelets should be removed from the red cells, preferably within 24 hours of collection. If component preparation is not possible, whole blood can be leuko (and platelet)-reduced by filtration, inducing a component-like stability of the red cells stored in the plasma. ${ }^{27}$

\section{Leukoreduction}

The presence of leukocytes in blood components can induce several adverse effects following blood transfusion, such as febrile non-hemolytic reactions (FNHTR), ${ }^{28,29}$ HLA-immunization followed by refractoriness to platelet transfusions, ${ }^{30}$ and transmission of bacteria or viruses (and possibly some parasites), and also contribute to deterioration of the product during storage. To increase the safety of transfusion, leukocyte removal from blood or blood components is preferred. Removal of the buffy coat reduces the number of leukocytes in red cell concentrates (RCCs) from approximately $3 \times 10^{9}$ to $<1 \times 10^{9}$ and prevents the formation of microaggregate during storage. ${ }^{31,32}$ Transfusion of buffy coat-poor red cells induced approximately $50 \%$ fewer febrile transfusion reactions compared with whole blood or buffy coat-containing red cells. ${ }^{33,34}$ However, to prevent HLA immunization, the number of residual leukocytes should be reduced to $<5-10 \times 10^{6}$, that is, a $3 \log _{10}$ reduction $(99.9 \%$ reduction). ${ }^{30}$

To remove leukocytes to such a low number from cellular blood components in a closed system on a large scale, filtration is the method of choice (though some apheresis devices use centrifugation or other techniques). The first leukoreduction filters intended for whole blood or RCCs were made of nylon ${ }^{35}$ or cotton wool. ${ }^{36}$ Presently, filters consist of a hard or soft housing filled with various layers of nonwoven material such as polyester, ${ }^{37}$ polyurethane, or other blow molded materials. ${ }^{38}$ The number of layers with a certain pore size, biocompatibility, electric charge, and wettability may all be varied to optimize the filtration mechanisms for the specific blood component. ${ }^{37-40}$ Mechanisms of filtration 
of leukocytes from whole blood or RCC are direct adhesion of the leukocytes to the filter fibers; indirect adhesion, where first platelets attach to the fibers and next leukocytes to the platelets; and sieving in which the leukocytes are captured in the pores of the filter. ${ }^{37-40}$

Many variables play a role in filtration, such as composition of the component (number and type of cells, hematocrit, medium), temperature, priming and rinsing, and age; ${ }^{39}$ variables that play a role specifically for platelets are activation, biocompatibility of the fiber, speed of filtration, and aggregation. ${ }^{38}$ Thus, each blood component needs a dedicated leukoreduction filter and filtration specifications. The process should be validated in routine and continuously checked on critical steps and followed up by quality control of the residual leukocyte count. Statistical process control of these data allows timely intervention when unexpected drifts occur. The Food and Drug Administration Guidance for industry describes all the requirements and steps of the leukoreduction process in detail and is of great value for those who want to improve quality aspects. ${ }^{41}$

Leukoreduction of blood components was already advised in the 1970s to prevent HLA alloimmunization and febrile reactions. ${ }^{28-30}$ Later, it was found that leukoreduction prevented hemolysis in $\mathrm{RCCs}^{42,43}$ and FNHTR after transfusion of leukocyte-poor platelet concentrates (PCs) by reduction of cytokine formation. ${ }^{44}$ Since the late 1990 s, many countries have introduced "universal" leukoreduction (ULR), meaning that all blood components are leukocyte-poor, some as a risk-reduction strategy for the transmission of variant Creutzfeldt Jakob Disease, others for other indications such as better quality of products. Additional advantages are having one processing method and one inventory (all products leukoreduced), which often lead to reduced costs.

Since the introduction of ULR, more clinical evidence has been published regarding significantly reduced FNHTR and HLA alloimmunization. ${ }^{45-48}$ Also there is evidence that transfusion of leukoreduced components is as safe as cytomegalo virus (CMV) negative blood components to prevent transmission of CMV. ${ }^{49,50}$ Much debated, but as yet with no conclusive opinion about the effect of leukoreduction, is the induction of immune-modulation. Transfusion of "foreign" leukocytes may induce a state of tolerance in the defense mechanisms of the recipient. ${ }^{51}$ On the one hand, the tolerance is preferred in case of, for instance, kidney transplantation; on the other hand, increased morbidity or mortality following multiple transfusions may be the effect. ${ }^{52}$ The implementation of ULR has made it almost impossible to do randomized controlled trials on this subject, since ethics committees cannot agree with a control group receiving non-leukoreduced components any more.

In conclusion, ULR has greatly improved the safety of blood transfusion. Currently, according to the American Association of Blood Banks (AABB) Standards, ${ }^{5}$ the residual number of leukocytes in a leukoreduced component should be $<5 \times 10^{6}$. The European Guide 4 is roughly equivalent and requires $<1 \times 10^{6}$ in $97 \%$ of the units tested and $<5 \times 10^{6}$ in $100 \%$.

\section{Red cell additive solutions}

Following centrifugation of whole blood, platelet-rich plasma or plasma and the buffy coat are removed from the red cells leaving only $10 \%-30 \%$ of the plasma (depending on the method of RCC preparation), which can be replaced by saline or red cell additive solutions (RASs). Plasma removal improved the safety for recipients by reduction of ABO isoantibodies, ${ }^{53,54}$ plasma proteins, ${ }^{54}$ and - if present HLA-antibodies from the donor. ${ }^{55}$ Blood group $\mathrm{O}$ red cells in additive solution can safely be used as universal RCC, while in the past, $A B$ substance had to be added to neutralize anti-A and anti-B antibodies prior to the transfusion to patients with blood groups other than $\mathrm{O}$.

The quality of RCCs and therewith the safety is highly influenced by the storage conditions: the storage temperature should be low to reduce metabolism and to prevent formation of "waste" products, as well as inhibit bacterial outgrowth, while enough nutrients have to remain available to maintain metabolism and adenosine triphosphate formation, ${ }^{56}$ and prevent hemolysis. ${ }^{42,43}$ At present, various RASs and rejuvenation solutions have been developed containing saline, adenine, guanine, dextrose, mannitol, and/or phosphate as reviewed by Hess. ${ }^{56}$ These RCCs have a shelf life of 5-6 weeks. Newly approved RASs allow a 7-week storage period, ${ }^{57}$ but experimental studies show a possible storage of up to 12 weeks. ${ }^{58}$

Safety aspects of prolonged storage of red cells are indirect, as it is possible to have inventories in various $\mathrm{ABO}$ and other blood groups, even in remote hospitals and in emergency situations, eliminating the use of blood from untested or partially tested donors.

\section{Platelet additive solutions}

Platelet additive solutions (PASs) have in principle the same benefits as RASs by partial replacement of plasma as storage medium for platelets. However, with the current generation of PAS, still approximately $30 \%-35 \%$ of plasma is needed to maintain platelet quality. ${ }^{59}$ PASs contain acetate to replace 
glucose as fuel for the platelets, which effectively prevents acidification of the storage environment. ${ }^{60}$ Other ingredients have been added to PAS, and currently, based on in vitro parameters, platelets stored in PAS have better in vitro characteristics than those stored in plasma, depending on the specific composition of the PAS (potassium and magnesium seem to be important in this respect) ${ }^{61}$ Clinical effectiveness of apheresis platelets stored in these potassium- and magnesium-containing PASs is superior to plasma with respect to platelet recovery and survival, ${ }^{62}$ giving great promise for the future, but more clinical data are needed.

Transfusion of platelets in PAS give fewer allergic reactions, and the occurrence is about half of that found for plasma. ${ }^{63-66}$ As an alternative for male-only plasma to prevent TRALI, PASs have been suggested. ${ }^{67}$ Because of the rare occurrence of TRALI, large post-marketing studies are necessary to demonstrate a reduction in frequency. It is a matter of debate whether the remaining percentage plasma, that is, approximately $25-30 \mathrm{~mL}$ from each of the buffy coats added to a PC, is sufficient to mitigate TRALI. Case reports have shown that even $10 \mathrm{~mL}$ of plasma in a RCC was sufficient to evoke TRALI. ${ }^{55} \mathrm{~A}$ comparison of bacterial growth in platelet stored in plasma or in PAS revealed that bacteria have shorter lag phase in PAS, resulting in a higher bacterial load after 24 hours; however, the maximum concentration was not different. ${ }^{68}$ The authors speculate that this may present an early bacterial detection advantage for PAS-stored PCs.

In summary, the use of PAS leads to fewer allergic reactions and to better storage conditions than in plasma, though more clinical data (platelet increments or bleeding tendency) following transfusion of platelets stored in various PAS need to be generated, keeping in mind that specific constituents of the PAS can affect the clinical outcomes.

\section{Separation equipment Automated separators}

Machines to automatically separate centrifuged whole blood in individual components, ie, red cells, plasma, and a buffy coat or a platelet product became available in the late 1980s. Until then, it was performed manually by placing the centrifuged whole blood in a so-called plasma extractor (a clamp). Well-trained staff literally had to keep an eye on the separation process and had to clamp the tubing when one component was expressed to a satellite bag and open a different tubing to express the next component to another satellite bag. ${ }^{69}$ Along with the development of the bottom-and-top collection system (with pieces of tubing connected to satellite bags at the top and at the bottom of the collection bag), automated devices were developed..$^{70} \mathrm{At}$ present, with automated cannula breakers, "electronic eyes", clamps, presses, detectors, flow speed controllers, and sealing heads, the blood separation process is fully controlled. ${ }^{71}$ It needs less human oversight and has led to more standardized and uniform composition of the blood components. A further benefit is that these devices allow full documentation of the processing by barcode scanning (staff ID, instrument ID, bag ID, program used, time, components obtained, $\mathrm{OK} /$ not OK) and integration into the main blood bank software. Particularly, the composition of the buffy coat, as source for further platelet isolation, became highly standardized..$^{70,71}$

These automated separators still require a manual step where the centrifuged whole blood is transferred to the separator. Since the 1990s, machines that integrate centrifugation and component separation in one process have been developed. This dynamic process has benefits, as variations in centrifugation speed and detection systems are applied to optimize separation of components, resulting in higher yields. Such devices exist for whole blood, that is separated into red cells, plasma, and either a buffy coat ${ }^{72,73}$ or an "intermediate platelet unit" $" 74,75$ that can be pooled without a secondary centrifugation step. Alternatively, the device can process buffy coat pools into a PC. ${ }^{76,77}$ In addition to the practical benefits (processing time, floor space, etc), a clear benefit is the reduction of the number of manual steps (each of which can go wrong and require extensive training of staff) and full documentation of the automated process. Though the underlying donor variation, for example hematocrit and platelet count, induce the largest variations in the final blood components, the use of electronic detection systems will result in a more standardized blood product with fewer outliers, and the average yield is higher.

In the Amsterdam blood center, GMP and quality systems were introduced in the late 1980s. Automation was introduced in the 1990s, which has resulted in a rigorous standardization of the blood component preparation process as shown in an example for pooled buffy coats. ${ }^{78}$ Keeping in mind that the source material has its natural donor variation, the current process aims at products that are within specifications in at least $95 \%$ and preferably $>99 \%$ of the tested units. ${ }^{4,5}$ Continuous monitoring of the process and quality control testing on a regular base allow timely interventions. In the Netherlands, in 2014, 434,000 units of leukoreduced RCCs were processed; all of the 1,475 randomly tested units met the $\mathrm{Hb}>40$ g per unit specification and contained $52 \pm 5 \mathrm{~g} \mathrm{Hb}$ (mean $\pm \mathrm{SD}$ ) and fewer than $1 \times 10^{6}$ leukocytes $(100 \%$, unpublished QC data). For the leukoreduced platelet pools from $5 \mathrm{BC}$ in plasma in January 2015, 1,140 were processed and tested 
and contained $342 \pm 50 \times 10^{9}$ platelets (mean $\pm \mathrm{SD}$ ), $1 \%$ did not meet the minimum number of $235 \times 10^{9}$, and all contained $<1 \times 10^{6}$ leukocytes.

\section{Apheresis}

An alternative for whole blood collection is apheresis, where only the desired component or components are collected, and the remainder is returned to the donor. Various devices have been developed, implementing centrifugation, surge, and leukodepletion techniques, to optimize yields of specific cells, purity of the product, and predicted outcome. A major safety aspect of apheresis is the possibility to collect a therapeutic dose of specific blood cells or plasma from one donor. The donor is selected based on the red cell, HLA, or HPA antigens to avoid adverse reactions due to alloantibodies. Specifically to collect stem cells, dendritic cells, granulocytes, HLA- and/or HPA-typed platelets, or typed RCCs, apheresis is the method of choice.

Apheresis can also be applied to collect red cells, plasma, or platelets at random, and then it has the advantage of reduction of donor exposure. Vamvakas ${ }^{79}$ showed that in the USA, the very small risk of TTI through transfusion is at least two times higher for whole blood-derived platelets than for apheresis platelets. However, others showed that provided leukoreduction is performed, no difference in the frequency of adverse transfusion reactions was found. ${ }^{80,81}$

Much more recent is the random collection of RCCs by apheresis. For reasons of cost efficiency, usually two RCCs are collected from one donor. ${ }^{82}$ If both units are allocated to one patient, donor exposure can be decreased. Also, in theory, the hemoglobin content per unit can be better predicted, and from that the number of RCC units to be transfused, in contrast to the sometimes broad hemoglobin distribution observed in RCCs from whole blood can be predicted. ${ }^{83,84}$ Thus, the safety benefit of randomly collected blood components with apheresis is mainly reduction of donor exposure, although the overall cost, as well as the donor willingness to undergo a long apheresis procedure, should be considered.

\section{Bacterial testing}

Having a fully closed system for collection of blood, as well as having the ability to connect separate bags with a sterile connection device, already significantly reduced the risk of bacterial contamination of blood components. As recently reviewed by De Korte and Marcelis, ${ }^{85}$ a variety of additional measures including improved skin disinfection, diversion of the first milliliters of drawn blood, and pre-storage culturing and delivery as "negative to date" or post-storage screening to detect bacterial contamination of blood components have further decreased the occurrence of adverse reactions on contaminated blood. While approximately 1:1,000 cultured units are false-negative, the actual risk of a septic transfusion reaction due to outgrowth of bacteria is estimated at 1:100,000; fatalities are estimated at 1:1,000,000 transfusions. ${ }^{85}$

\section{Pathogen reduction}

Various systems for pathogen reduction have been developed. Some are intended only for pathogen reduction of plasma, some for plasma and PCs, and others for RCCs. ${ }^{86}$ Currently, methods are being developed to treat whole blood, which will give multiple pathogen-reduced components.

The various systems will not be discussed in detail here. All currently marketed technologies have adequate inactivation capacity to prevent the transmission of viruses, bacteria, and parasites. What they have in common is that there is some loss of clinical effectiveness. As an example, for PCs, pathogen reduction results in lower platelet increments after transfusion, ${ }^{65,87}$ which in theory results in more transfusions, as the transfusion trigger is met sooner. The same is true for pathogen-reduced red cells and plasma/clotting factors. However, there is a clear trade-off: though the patient may receive more transfusions, they do receive products that are safe regarding TTI. How much quality can be given up for increased safety and to what cost is a matter of debate.

For low-income countries, weighing the cost as well as the degree of pathogen kill, pathogen reduction technologies may solve a lot of problems in endemic areas for hepatitis B virus, hepatitis $\mathrm{C}$ virus, and human immunodeficiency virus and also for emerging diseases such as dengue, chikungunya, Chagas disease, and malaria. For each individual method of pathogen reduction, the consideration should be made whether all viral screening tests need to be continued or that pathogen reduction could replace some of these tests, making it more cost-efficient. Studies are still being undertaken to demonstrate clinical effectiveness of treated blood products and to investigate other side effects (neo antigen formation) of the process.

Overall, pathogen-reduction procedures are generally accepted for plasma and are gaining popularity for platelets as a measure to increase the safety for patients and are under investigation for RCCs and whole blood. Though some loss in product quality is observed, it is generally considered to be an acceptable trade-off for the increased safety of the product, keeping in mind the increased cost.

\section{Transfusion guidelines}

Despite improved possibilities to test for TTI, to reduce processing losses, to standardize the composition of components, 
and to have quality systems in place, clinical guidelines to decide for blood transfusion and administer the blood and blood components are also cornerstones to improve safety around blood transfusion. In many countries, clinical guidelines (where possible evidence based) have been developed as reviewed by Goodnough et $\mathrm{al}^{88}$, and it is advised to have hospital blood transfusion committees with members from the blood bank and the various hospital divisions to make specific hospital guidelines. Combined with adequate software, these allow the transfusion laboratories to ensure the best component for a specific patient and have good inventory management in the hospitals. ${ }^{89}$ For the physicians, guidelines improve decision-making based on transfusion triggers, ${ }^{88}$ complemented with patient criteria and information on composition of the components to reduce donor exposure. For the nurses, the clinical guidelines explain how to administer the components and how to react and document if adverse reactions occur. Systems of monitoring all serious adverse reactions, that is, a Hemovigilance system should be included in these guidelines. ${ }^{10,88}$

\section{Summary}

To improve safety, blood donations and the components derived from whole blood need to be traced from donor to the recipient applying a cGMP-based Quality system. Whole blood is preferably collected from repeat donors, either voluntary or replacement donors. Separation of whole blood into components allows treating a patient with only the product needed, thus preventing adverse reactions. Particularly, removal of leukocytes leads to a significant reduction of adverse reactions and improvement of safety of blood components. Replacement of plasma by storage solutions for red cells and platelets leads to a reduction

Table I Summary of improvements in processing and storage of blood components, their effect, and the impact on the safety

\begin{tabular}{|c|c|c|}
\hline Improvement & Effect & Impact on safety \\
\hline \multirow[t]{2}{*}{ Quality system (GMP) } & Validated documented processes, standard procedures, certified staff & High \\
\hline & $\begin{array}{l}\text { Traceability of all materials, reagents, equipment, staff, and components from } \\
\text { donor to patient }\end{array}$ & High \\
\hline \multirow[t]{3}{*}{ Repeat donors } & Lower risk for TTI & High \\
\hline & Repeat ABO (HLA, HPA) testing & Intermediate-high \\
\hline & Donor database & \\
\hline \multirow[t]{2}{*}{ Closed bag systems } & Reduction of bacterial risk & High \\
\hline & Prolonged storage time & Intermediate \\
\hline \multirow[t]{4}{*}{ Blood component separation } & Patient treated with component that is needed, reduction of adverse reactions & High \\
\hline & More patients treated with one donation & Low \\
\hline & Plasma available for clotting factor concentrates & Low \\
\hline & Buffy coat removal improves quality of red cell concentrates & Intermediate-high \\
\hline \multirow[t]{4}{*}{ Leukoreduction } & Prevention of HLA alloimmunization & Intermediate-high \\
\hline & Prevention of FNHTR & Intermediate \\
\hline & Prevention of transmission of cell-bound viruses & Low-intermediate \\
\hline & Induction of immune-modulation & Unknown \\
\hline \multirow[t]{2}{*}{ Red cell additive solutions } & Reduction of $A B$ isoantibodies & Intermediate \\
\hline & Improvement of quality and storage & Low-intermediate \\
\hline \multirow[t]{4}{*}{ Platelet additive solutions } & Reduction of $A B$ isoantibodies & Intermediate \\
\hline & Reduction of allergic reactions & Intermediate \\
\hline & Improvement of quality & Intermediate \\
\hline & Prevention of TRALI & Unknown \\
\hline \multirow[t]{3}{*}{ Automated separators } & Reduction of manual steps & Intermediate \\
\hline & Standardized products & Intermediate \\
\hline & Improved traceability & Intermediate-high \\
\hline \multirow[t]{2}{*}{ Automated component processors } & Less human intervention and training & Intermediate \\
\hline & Standardization and traceability & Intermediate \\
\hline \multirow[t]{2}{*}{ Apheresis selected donor } & Therapeutic component dose for alloimmunized patient & High \\
\hline & Therapeutic dose of stem cells, dendritic cells, or granulocytes for specific patient & High \\
\hline \multirow[t]{2}{*}{ Apheresis random donor } & Single donor, therefore lower risk of TTI & Intermediate \\
\hline & Standardized products & Low-intermediate \\
\hline Pathogen reduction & Lower risk of TTls & Low-care countries: high \\
\hline Transfusion guidelines & Improved clinical knowledge; transfusion based on transfusion triggers preventing & Intermediate-high \\
\hline Hospital transfusion Committees & excess transfusion, hemovigilance & \\
\hline
\end{tabular}

Abbreviations: GMP, good manufacturing practice; TTI, transfusion-transmitted infection; HLA, human leukocyte antigen; HPA, human platelet antigen; FNHTR, febrile non-hemolytic reaction; TRALI, transfusion-related acute lung injury. 
of isoantibodies, HLA-antibodies if present, and plasma proteins and allow addition of specific nutrients to improve and extend storage of the red cells or platelets. The use of automated equipment, both component separators and apheresis devices, reduces the number of manual steps and lead to standardization of the blood component, which allow the physician to better predict the expected transfusion outcome. Apheresis has the additional benefit that a therapeutic dose can be obtained from a donor selected on specific blood group antigens or more of the desired cells or plasma can be obtained from a single donor, reducing the risk of TTI transmission. Pathogen reduction technologies further reduce that risk and may be of value in providing a safe transfusion product. In Table 1, we aimed to indicate the potential impact of all these different optimization, standardization, and quality measures on the ultimate transfusion chain from the donor to the recipient. Of course, the degree of impact is debatable and can vary considerably from region to region, but it may assist in setting priorities when funding or staffing sources are limited. In all, these strategies improve the safety of the transfused patient.

\section{Acknowledgments}

We thank Dr Dirk de Korte (Manager, Department of Product and Process Development, Sanquin Blood Bank, Amsterdam, the Netherlands) for critical revision of the manuscript and for helpful suggestions.

\section{Disclosure}

The authors report no conflicts of interest in this work.

\section{References}

1. Commission Directive 2003/94/EC of 8 October 2003 laying down the principles and guidelines of good manufacturing practice in respect of medicinal products for human use and investigational medicinal products for human use. Off J Eur Union. 2003;L262:22.

2. PIC/S GMP guide for blood establishments. Pharmaceutical Inspection Convention. Pharmaceutical Inspection Co-operation Scheme; 2007; PE 005-3. Available from: http://www.picscheme.org/pdf/21_pe-005-3-pics-gmp-guide-for-blood-establishments.pdf. Accessed July 27, 2015.

3. Directive 2002/98/EC of the European Parliament and of the Council of January 2003 setting standards of quality and safety for the collection, testing, processing, storage and distribution of human blood and blood components and amending Directive 2001/83/EC. Off J Eur Union. 2003;L33:30.

4. Guide to the Preparation, Use and Quality Assurance of Blood Components. European Directorate for the Quality of Medicines and Healthcare (EDQM) of the Council of Europe. 17th ed. France: Strasbourg; 2013.

5. Standards for Blood Banks and Transfusion Services. American Association for Blood Banks (AABB). 28th ed. Maryland: Bethesda; 2012.

6. Commission Directive 2004/33/EC of March 2004 implementing Directive 2002/98/EC of the European Parliament and of the Council as regards certain technical requirements for blood and blood components. Off $J$ Eur Union. 2004;L91:25.
7. PIC/S Recommendations on validation master plan, installation operational qualification, non-sterile process validation, cleaning validation. Pharmaceutical Inspection Convention. Pharmaceutical Inspection Co-operation Scheme; 2007;PI 006-3. Available from: http://www. picscheme.org/pdf/25_pi-006-3-recommendation-on-validation-masterplan.pdf. Accessed July 27, 2015.

8. Commission Directive 2005/62/EC of September 2005 implementing Directive 2002/98/EC of the European Parliament and of the Council as regards community standards and specifications relating to a quality system for blood establishments. Off J Eur Union. 2005;L256:41.

9. Aide Mémoire for National Blood programmes. Quality systems for blood safety. World Health Organization. WHO/BCT/02.02 2002 reprinted 2009. Available from: http://apps.who.int/medicinedocs/ documents/s17255e/s17255e.pdf. Accessed July 27, 2015.

10. Commission Directive 2005/61/EC as of 30 September 2005 implementing Directive 2002/98/EC of the European Parliament and of the Council as regards traceability requirements and notification of adverse reactions and events. Off J Eur Union. 2005;L256:32.

11. International Society of Blood Transfusion (ISBT) Working Party on Information Technology Task Force. ISBT Guidelines for validation of automated systems in blood establishments. Vox Sang. 2003;98(Suppl 1).

12. International Society of Blood Transfusion (ISBT) Working Party on Information Technology Task Force. ISBT Guidelines for validation of automated systems in blood establishments. Vox Sang. 2010;98 (Suppl 1):1-15.

13. Van der Bij AK, Coutinho RA, Van der Poel CL. Surveillance of risk profiles among new and repeat donors with transfusion-transmissible infections from 1995 through 2003 in the Netherlands. Transfusion. 2006; 46:1729-1736.

14. Roth WK, Busch MP, Schuller A, et al; International Forum. International survey on NAT testing of blood donations: expanding implementation and yield from 1999 to 2009. Vox Sang. 2012;102:82-90.

15. Bruhn R, Lelie N, Custer B, Busch M, Kleinman S; The International NAT Study Group. Prevalence of human immunodeficiency virus RNA and antibody in first-time, lapsed and repeat blood donations across five international regions and relative efficacy of alternative screening scenarios. Transfusion. 2013;53:2399-2412.

16. Lieshout-Krikke RW, Zaaijer HL, Van de Laar TJW. Predonation screening of candidate donors and prevention of window period donations. Transfusion. 2015;55:373-378.

17. Allain JP. Moving on from voluntary non-remunerated donors: who is the best donor? Br J Haematol. 2011;154:763-769.

18. Allain JP. Volunteer safer than replacement donor blood: myth revealed by evidence. ISBT Sci Ser. 2010;5:169-175.

19. Devine DG, Sher GD, Reesink HW, et al; International Forum. Inventory management. Vox Sang. 2010;98:295-363.

20. Mollison P. Historical review. The introduction of citrate as an anticoagulant for transfusion and of glucose as a red cell preservative. $\mathrm{Br} J$ Haematol. 2000;108:13-18.

21. Åkerblom O, Kreuger A. Studies on citrate-phosphate-dextrose (CPD) blood supplemented with adenine. Vox Sang. 1975;29:90-100.

22. Vogel P. Current problems in blood transfusion. Bull N Y Acad Med. 1954;30:657-674.

23. James JD. Editorial. Bacterial contamination of preserved blood. Vox Sang. 1959;4:177-185.

24. Borden CW, Hall WH. Fatal transfusion reactions from massive bacterial contamination of blood. N Engl J Med. 1951;245:760-765.

25. Walter CW. Invention and development of the blood bag. Vox Sang. 1984;47:318-324.

26. Swank RL. Alteration of blood on storage: measurements of adhesiveness of "aging" platelets and leukocytes and their removal by filtration. N Engl J Med. 1961;265:728-733.

27. Picker AM, Stürner SS, Oustianskaja L, Gathof BL. Leukodepletion leads to component-like storage stability of whole blood-suggesting its homologous use? Vox Sang. 2004;87:173-181. 
28. Payne R. The association of febrile transfusion reactions with leukoagglutinins. Vox Sang. 1957;2:233-241.

29. Perkins HA, Payne R, Ferguson J, Wood M. Non hemolytic febrile transfusion reactions. Quantitative effects of blood components with emphasis on isoantigenic incompatibility of leukocytes. Vox Sang. 1966;11:578-600.

30. Eernisse G, Brand A. Prevention of platelet refractoriness due to HLA antibodies by administration of leukocyte-poor components. Exp Haematol. 1981;9:77-83.

31. Prins HK, de Bruijn JCGH, Henrichs HPJ, Loos JA. Prevention of microaggregate formation by removal of "buffy-coats". Vox Sang. 1980;39:48-51.

32. Högman CF, Johansson A. A simple method for the preparation of microaggregate-poor whole blood. Vox Sang. 1981;40:286-288.

33. Liedén G, Hildén J-O. Febrile reactions reduced by buffy-coat-poor erythrocyte concentrates. Vox Sang. 1982;43:263-265.

34. Högman CF, Åkerblom O, Hedlund K, Rosén I, Wiklund L. Red cell suspensions in SAGM medium. Further experience of in vivo survival of red cells, clinical usefulness and plasma-saving effects. Vox Sang. $1983 ; 45: 217-233$.

35. Greenwalt TJ, Gajewsky M, McKenna JL. A new method for preparing buffy coat-poor blood. Transfusion. 1962;1:221-229.

36. Diepenhorst P, Sprokholt R, Prins HK. Removal of leukocytes from whole blood and erythrocyte suspensions by filtration through cotton wool. I. Filtration technique. Vox Sang. 1972;23:308-223.

37. Steneker I, Biewenga J. Histologic and immunohistochemical studies on the preparation of white-cell poor red cell concentrates: the filtration process using three different polyester filters. Transfusion. 1991;31: 40-46.

38. Bruil A, Beugeling T, Feijen J, Van Aken WG. The mechanisms of leukocyte removal by filtration. Transfus Med Rev. 1995;IX:145-166.

39. Steneker I, Prins HK, Florie M, Loos JA, Biewenga J. Mechanisms of white cell reduction in red cell concentrates by filtration: the effect of the cellular composition of the red cell concentrates. Transfusion. 1992;32:42-50.

40. Steneker I, Van Luijn MJA, Van Wachem PB, Biewenga J. Electron microscopic examination of white cell reduction by four white cellreduction filters. Transfusion. 1992;32:450-457.

41. FDA. Guidance for Industry: Pre-Storage Leukocyte Reduction of Whole Blood and Blood Components Intended for Transfusion; 2012. Available from: http://www.fda.gov/BiologicsBloodVaccines/ GuidanceComplianceRegualtoryInformation/Guidances/default.htm.

42. Högman CF, Hedlund $\mathrm{K}$, Åkerblom O, Venge P. Red blood cell preservation in protein-poor media. I. Leukocyte enzymes as a cause of hemolysis. Transfusion. 1978;18:233-241.

43. Brecher ME, Pineda AA, Torlone AS. Prestorage leukocyte depletion: effect on leukocyte and platelet metabolites, erythrocyte lysis, metabolism and in vivo survival. Semin Hematol. 1991;28:3-9.

44. Muylle L, Peetermans ME. Effect of prestorage leukocyte removal on the cytokine levels in stored platelet concentrates. Vox Sang. 1994;66: 14-17.

45. Heddle NM, Blajchman MA, Meyer RM, et al. A randomized controlled trial comparing the frequency of acute reactions to plasma-removed platelets and prestorage WBC-reduced platelets. Transfusion. 2002;42: 556-566.

46. Yazer MH, Podlosky L, Clarke G, Nahirniak SM. The effect of prestorage WBC reduction on the rates of febrile nonhemolytic transfusion reactions to platelet concentrates and RBC. Transfusion. 2004;44: 10-15.

47. Paglino JC, Pomper GJ, Fisch GS, Champion MH, Snyder EL. Reduction of febrile but not allergic reaction to RBCs and Platelets after conversion to universal prestorage leukoreduction. Transfusion. 2004;44:16-24.

48. King KE, Shirey RS, Thoman SK, Bensen-Kennedy D, Tanz WS, Ness PM. Universal leukoreduction decreases the incidence of febrile non hemolytic transfusion reaction to RBCs. Transfusion. 2004;44:25-29.

49. Preiksaitis JK. The cytomegaly virus-"safe" blood product: is leukoreduction equivalent to antibody screening? Transfus Med Rev. 2000;14: 112-136.
50. Laupacis A, Brown J, Costello B, et al. Prevention of CMV transmission in the era of universal WBC reduction: a consensus statement. Transfusion. 2001;41:560-569.

51. Opelz G, Sengar DP, Mickey MR, Terasaki PI. Effect of blood transfusions on subsequent kidney transplants. Transplant Proc. 1973;5: 253-259.

52. Waanders M, Van de Watering L, Brand A. Immunomodulation and allogeneic blood transfusion. Transfus Altern Transfus Med. 2008;10:127-138.

53. Ebert RV, Emerson CP Jr. A clinical study of transfusion reactions: the hemolytic effect of group-O blood and pooled plasma containing incompatible isoagglutinins. J Clin Invest. 1946;25(4):627-638.

54. Berséus O, Boman K, Nessen SC, Westerberg SA. Risks of hemolysis due to anti-A and anti-B caused by the transfusion of blood or blood components containing ABO-incompatible plasma. Transfusion. 2013;53:114S-123S.

55. Win N, Chapman CE, Bowles KM, et al. How much residual plasma may cause TRALI? Transfus Med. 2008;18:276-280.

56. Hess JR. An update on solutions for red cell storage. Vox Sang. 2006; 92:13-19.

57. Cancelas JA, Dumont LJ, Maes LA, et al. Additive solution-7 reduces the red blood cell cold storage lesion. Transfusion. 2015;55:491-498.

58. Hess JR, Hill HR, Oliver CK, et al. Twelve-week RBC storage. Transfusion. 2003;43:867-872.

59. Klinger MH, Josch M, Klüter H. Platelets stored in a glucose-free additive solution or in autologous plasma - an ultrastructural and morphometric evaluation. Vox Sang. 1996;71:13-20.

60. Murphy S. The oxidation of exogenously added organic anions by platelets facilitates maintenance of $\mathrm{pH}$ during their storage for transfusion at 22 degrees C. Blood. 1995;85:1929-1935.

61. van der Meer PF, Kerkhoffs JL, Curvers J, et al. In vitro comparison of platelet storage in plasma and in four platelet additive solutions, and the effect of pathogen reduction: a proposal for an in vitro rating system. Vox Sang. 2010;98:517-524.

62. Slichter SJ, Corson J, Jones MK, et al. Exploratory studies of extended storage of apheresis platelets in a platelet additive solution (PAS). Blood. 2014;123:271-280.

63. De Wildt-Eggen J, Nauta S, Schrijver JG, van Marwijk Kooy M, Bins M, van Prooijen HC. Reactions and platelet increments after transfusion of platelet concentrates in plasma or an additive solution: a prospective, randomized study. Transfusion. 2000;40:398-403.

64. Kerkhoffs JL, Eikenboom JC, Schipperus MS, et al. A multicenter randomized study of the efficacy of transfusions with platelets stored in platelet additive solution II versus plasma. Blood. 2006;108:3210-3215.

65. Cohn CS, Stubbs J, Schwartz J. A comparison of adverse reaction rates for PASC versus plasma platelet units. Transfusion. 2014;54:1927-1934.

66. Tobian AA, Fuller AK, Uglik K, et al. The impact of platelet additive solution apheresis platelets on allergic transfusion reactions and corrected count increment (CME). Transfusion. 2014;54:1523-1529.

67. Insunza A, Romon I, Gonzalez-Ponte ML, et al. Implementation of a strategy to prevent TRALI in a regional blood centre. Transfus Med. 2004;14:157-164.

68. Dumont LJ, Wood TA, Housman M, et al. Bacterial growth kinetics in ACD-A apheresis platelets: comparison of plasma and PAS III storage. Transfusion. 2011;51:1079-1085.

69. Pietersz RN, Reesink HW, Dekker WJ, Fijen FJ. Preparation of leukocyte-poor platelet concentrates from buffy coats. I. Special inserts for centrifuge cups. Vox Sang. 1987;53:203-207.

70. Högman CF, Eriksson L, Hedlund K, Wallvik J. The bottom and top system: a new technique for blood component preparation and storage. Vox Sang. 1988;55:211-217.

71. Bontekoe IJ, van der Meer PF, Mast G, de Korte D. Separation of centrifuged whole blood and pooled buffy coats using the new CompoMat G5: 3 years experience. Vox Sang. 2014;107:140-147.

72. Thomas S, Beard M, Garwood M, Callaert M, Van Waeg G, Cardigan R. Blood components produced from whole blood using the Atreus processing system. Transfusion. 2008;48:2515-2524. 
73. Lotens A, Najdovski T, Cellier N, Ernotte B, Lambermont M, Rapaille A. New approach to 'top-and-bottom' whole blood separation using the multiunit TACSI WB system: quality of blood components. Vox Sang. 2014;107:261-268.

74. Sandgren P, van Waeg G, Verheggen C, Sjödin A, Gulliksson H. Storage of interim platelet units for 18 to 24 hours before pooling: in vitro study. Transfusion. 2011;51:1213-1219.

75. Lagerberg JW, Salado-Jimena JA, Löf H, et al. Evaluation of the quality of blood components obtained after automated separation of whole blood by a new multiunit processor. Transfusion. 2013;53: 1798-1807.

76. Janetzko K, Klüter H, van Waeg G, Eichler H. Fully automated processing of buffy-coat-derived pooled platelet concentrates. Transfusion. 2004;44:1052-1058.

77. Sandgren P, Hild M, Sjödin A, Gulliksson H. Storage of buffy-coatderived platelets in additive solutions: in vitro effects on platelets prepared by the novel TACSI system and stored in plastic containers with different gas permeability. Vox Sang. 2010;99:341-347.

78. Pietersz RN, van der Meer PF, Steneker I, et al. Preparation of leukodepleted platelet concentrates from pooled buffy coats: prestorage filtration with Autostop ${ }^{\text {TM }}$ BC. Vox Sang. 1999;76:231-236.

79. Vamvakas EC. Relative safety of pooled whole blood-derived versus single-donor (apheresis) platelets in the United States: a systematic review of disparate risks. Transfusion. 2009;49:2743-2758.

80. Schrezenmeier H, Seifried E. Buffy-coat-derived pooled platelet concentrates and apheresis platelet concentrates: which product type should be preferred? Vox Sang. 2010;99:1-15.
81. Heddle NM, Arnold DM, Boye D, Webert KE, Resz I, Dumont LJ. Comparing the efficacy and safety of apheresis and whole bloodderived platelet transfusions: a systematic review. Transfusion. 2008;48: 1447-1458.

82. Shi PA, Ness PM. Two-unit red cell apheresis and its potential advantages over traditional whole-blood donation. Transfusion. 1999; $39: 218-225$

83. Högman CF, Meryman HT. Red blood cells intended for transfusion: quality criteria revisited. Transfusion. 2006;46:137-142.

84. Arslan Ö, Toprak S, Arat M, Kayalak Y. Hb-content based transfusion policy successfully reduces the number of RBC units transfused. Transfusion. 2004;44:485-488.

85. De Korte D, Marcelis JH. Platelet concentrates: reducing the risk of transfusion-transmitted bacterial infections. Int J Clin Transl Med. 2014;2:29-37.

86. Salunkhe V, van der Meer PF, de Korte D, Seghatchian J, Gutiérrez L. Development of blood transfusion product pathogen reduction treatments: a review of methods, current applications and demands. Transfus Apher Sci. 2015;52:19-34.

87. Mirasol Clinical Evaluation Study Group. A randomized controlled clinical trial evaluating the performance and safety of platelets treated with MIRASOL pathogen reduction technology. Transfusion. 2010;50: 2362-2375.

88. Goodnough LT, Levy JH, Murohy MF. Concepts of blood transfusion in adults. Lancet. 2013;381:1845-1854.

89. Butch S. Editorial. Automating the transfusion service in the 21st century. Transfusion. 2008;48:406-407.
International Journal of Clinical Transfusion Medicine

\section{Publish your work in this journal}

International Journal of Clinical Transfusion Medicine is an international, peer-reviewed, open access, online journal publishing clinicalexperimental, policy-making and evidence-based practices of all topics pertaining to clinical transfusion medicine. Original research, short reports, reviews, case reports and commentaries are invited.

\section{Dovepress}

The manuscript management system is completely online and includes a very quick and fair peer-review system, which is all easy to use. Visit http://www.dovepress.com/testimonials.php to read real quotes from published authors. 